\title{
Optimization of drilling resistance measurement (DRM) user-controlled variables
}

\author{
Tudor F. Dumitrescu $(\mathbb{D} \cdot$ Giovanni L. A. Pesce $\mathbb{C} \cdot$ Richard J. Ball $\mathbb{D}$
}

Received: 2 August 2017 / Accepted: 7 November 2017/Published online: 17 November 2017

(C) The Author(s) 2017. This article is an open access publication

\begin{abstract}
Drilling resistance measurement (DRM) is recognised as an important on-site micro-invasive procedure for assessment of construction materials. This paper presents a detailed investigation of usercontrolled variables and their influence on drilling resistance. The study proves that the ratio of penetration rate/rotational speed is proportional to drilling resistance. Data from Bath stone and an artificial reference stone demonstrates how different materials can be compared using their intrinsic specific energy. It is also shown that adjusting drilling settings does not significantly change drilling measurement variability. However, settings producing high drilling resistance can significantly contribute to drill bit wear. A theoretical framework in which tests can be optimised without compromising the ability to compare data is presented. The framework is of high significance to the conservation industry and will promote a more effective use of DRM. DRM is a minimally invasive procedure particularly appropriate for sensitive heritage structures. Its use can provide the essential
\end{abstract}

T. F. Dumitrescu · R. J. Ball ( ()

Department of Architecture and Civil Engineering, BRE

Centre for Innovative Construction Materials (CICM),

University of Bath, Bath BA2 7AY, UK

e-mail: R.J.Ball@bath.ac.uk

\section{G. L. A. Pesce}

Department of Architecture and Built Environment, Northumbria University, Newcastle upon Tyne NE1 8ST, UK mechanical property data required for evaluation of surface consolidation products and specification of repair materials.

Keywords Drilling resistance $\cdot$ Bath stone $\cdot$ Uniaxial compressive strength $\cdot$ Stone conservation $\cdot$ Material characterisation

\begin{tabular}{|c|c|}
\hline \multicolumn{2}{|c|}{ Abbreviations } \\
\hline$A_{\mathrm{c}}$ & Area cut \\
\hline$A_{\mathrm{w}}$ & Area of the wear-flat \\
\hline ADR & Average drilling resistance \\
\hline ADR_R & Average drilling resistance per unit radius \\
\hline ARS & Artificial reference stone \\
\hline $\mathrm{COV}$ & Coefficient of variation \\
\hline$d_{\mathrm{c}}$ & Depth of cut per revolution \\
\hline DRC & $\begin{array}{l}\text { Drilling resistance for wear-correction } \\
\text { purposes }\end{array}$ \\
\hline DRMS & Drilling resistance measurement system \\
\hline DRM & $\begin{array}{l}\text { Drilling resistance measurement (referring } \\
\text { to the technique not actual measurements) }\end{array}$ \\
\hline$F_{\mathrm{c}}$ & Force at cutter interface \\
\hline$F_{\text {nc }}$ & Cutting component normal to the hole cut \\
\hline$F_{\text {nf }}$ & $\begin{array}{l}\text { Frictional component normal to the hole } \\
\text { cut }\end{array}$ \\
\hline$F_{\mathrm{f}}$ & Force on the wear-flat \\
\hline$F_{\text {tc }}$ & $\begin{array}{l}\text { Cutting component tangential to the hole } \\
\text { cut }\end{array}$ \\
\hline$F_{\mathrm{tf}}$ & $\begin{array}{l}\text { Frictional component tangential to the hole } \\
\text { cut }\end{array}$ \\
\hline
\end{tabular}


$F_{\text {n }} \quad$ Total normal cutting force

$F_{\mathrm{t}} \quad$ Total tangential cutting force

$n \quad$ Number of cutters on the drill bit

$r \quad$ Radius of the drill bit

PR Penetration rate

RPM Rotational speed in revolutions per minute

w Cutter width

$W \quad$ Weight-on-bit or drilling resistance

$\varepsilon \quad$ Intrinsic specific energy (energy required to cut a volume unit of material)

$\psi \quad$ Interfacial angle between cutter and the failed rock

$\mu \quad$ Ratio between the tangential and normal components of $F_{\mathrm{f}}$

$\theta \quad$ Backrake angle of the cutter

$\zeta \quad$ Ratio between the normal and tangential components of $F_{\mathrm{c}}$

$\lambda \quad$ Length of the wear flat

$\sigma \quad$ Contact stress on wear flat

\section{Introduction}

One of the very few on-site techniques that is appropriate for the assessment of the mechanical properties of modern and historic construction materials is drilling resistance measurement (DRM) [1,2]. The technique is based on the use of a portable drilling machine capable of measuring the drilling resistance and penetration depth of a drill bit, usually between 3 and $7 \mathrm{~mm}$ in diameter. Such systems maintain constant rotational speed (RPM) and penetration rate (PR) during the drilling operation. The DRM is an important technique in the conservation of historic buildings and in material characterisation. It can provide an important indication of the mechanical characteristics of a material and is particularly appropriate for investigation of changes in the subsurface with depth. In the conservation of historic buildings, the DRM has become an important resource since it is minimally invasive (the most common drill bit used in this field is $5 \mathrm{~mm}$ diameter) and allows the effect of degradation processes as well as of conservation treatments to be verified and monitored [1].

However, despite such interest, the micro-drilling technique isn't very well known. Few engineers and architects understand how the procedure works and how to interpret the data. Further work is necessary to show how the DRM can be used on-site to assess mechanical properties in the study of materials and conservation treatments.

Previous studies investigating the relationship between drilling resistance and uniaxial compressive strength (UCS) have thus far found no consistent relationship [1]. Similarly, other studies tried to relate the UCS to the drilling strength or energy required to cut a volume unit of material, commonly referred to as the intrinsic specific energy, $\varepsilon$. The previous correlations obtained between drilling resistance and UCS are not satisfactory, mainly because drilling resistance isn't only related to UCS, but also to other parameters imposed during the tests, such as: rate of penetration, rotation speed, drill bit radius and the state of drill bit wear, as shown by Eq. (13). As the intrinsic specific energy can be theoretically and empirically considered as a representation of a material's properties [3-7] it was suggested that the attempt to relate the drilling resistance to the UCS should be abandoned for the more direct approach of relating drilling resistance to the intrinsic specific energy [3, 7].

In addition, intrinsic specific energy is a parameter that allows the development of a procedure that can disentangle the impact of the other parameters on final results, and can be calculated from the weight on bit.

In this manner by comparing the intrinsic specific energy before and after application of a conservation treatment it would be possible to estimate the effect that a treatment had on the energy required to cut a specific volume of material. Furthermore, several studies $[3,7]$ have already shown that intrinsic specific energy is proportional to the uniaxial compressive strength of the material based on scratching tests.

This paper provides the theoretical framework and some experimental results supporting the relationship between uniaxial compressive strength, drilling resistance and intrinsic specific energy. The paper also describes the effects of changes in the rotational speed and penetration rate on the results of the drilling resistance of an artificial and natural stone. Results are discussed in relation to test speed, drill bit wear, and their variability. Recommendations for optimised settings are provided based on the materials investigated. 


\section{Theoretical framework}

Research on rock drilling in the petroleum industry using drag bits has shown that drilling resistance is proportional to the depth of cut per revolution [8]. For a DRM system, the depth of cut per revolution $\left(d_{\mathrm{c}}\right)$ is equal to the ratio of the penetration rate and rotational speed (PR/RPM), where penetration rate is measured in $\mathrm{mm}$ per min and the rotation speed in revolutions per minute, Eq. (1).

$d_{\mathrm{c}}=\frac{\mathrm{PR}}{\mathrm{RPM}}$.

This is part of a theoretical framework for drilling assuming a plastic flow mechanism, frictional contact between the cutters and the material, and a MohrCoulomb failure plane [4]. For a single blunt cutter Detournay and Defourny [8] have shown that the drilling process involves both a force (denoted ' $c$ ') on the cutter interface $\left(F_{\mathrm{c}}\right)$ and a force on the blunt wearflat $\left(F_{\mathrm{f}}\right.$; denoted ' $f$ '), as illustrated in Fig. 1. Each of these forces has two components, one normal to the hole cut (denoted ' $n$ ') and one tangential (denoted ' $t$ '). As a consequence, there are two normal components, $F_{\text {nc }}$ and $F_{\text {nf }}$, and two tangential components, $F_{\text {tc }}$ and $F_{\text {tf. }}$.
The total normal force, $F_{\mathrm{n}}$, and tangential force, $F_{\mathrm{t}}$, can be written in terms of the cutting force and frictional components by Eqs. (2) and (3) respectively.

$F_{\mathrm{n}}=F_{\mathrm{nc}}+F_{\mathrm{nf}}$.

$F_{\mathrm{t}}=F_{\mathrm{tc}}+F_{\mathrm{tf}}$.

For a drilling system, the area cut, $A_{\mathrm{c}}$, is equal to the product of the cutter width, $w$, and the depth of cut per revolution, $d_{\mathrm{c}}$, as described in Eq. (4).

$A_{\mathrm{c}}=w d_{\mathrm{c}}$.

The tangential force, $F_{\mathrm{tc}}$, can be written in terms of the intrinsic specific energy, $\varepsilon$, and the area cut, $A_{\mathrm{c}}$, as shown in Eq. (5), assuming a ductile failure mode.

$F_{t c}=\varepsilon A_{\mathrm{c}}$

For a drilling system, the frictional area of the wear flat, $A_{\mathrm{w}}$, attributed to a blunt cutter is the product of the cutter width $(w)$ and the length of the wear flat, $\lambda$, as described in Eq. (6).

$A_{\mathrm{w}}=w \lambda$.

The normal force, $F_{\mathrm{nf}}$, which is present if the tip of the cutter becomes blunt can be written in terms of the area, $A_{\mathrm{w}}$, and the contact stress on the wear flat, $\sigma$, by Eq. (7).

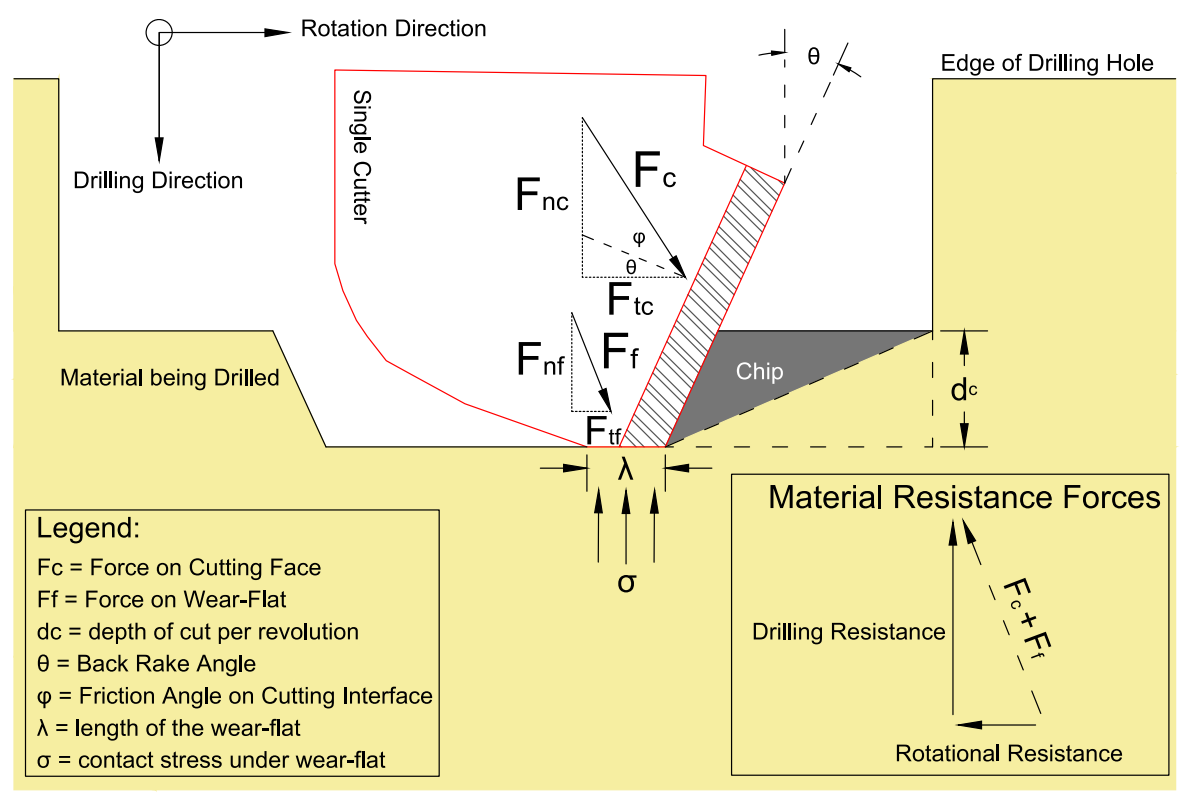

Fig. 1 Illustration of drilling mechanism for a single cutter. Adapted from Dagrain et al. [7] 
$F_{\mathrm{nf}}=\sigma A_{\mathrm{w}}$

The coefficient of friction, $\mu$, at the wear flat can be defined in terms of the ratio between the tangential and normal component of $F_{\mathrm{f}}[8]$, by Eq. (8).

$\mu=\frac{F_{\mathrm{tf}}}{F_{\mathrm{nf}}}$

The ratio of the normal and tangential components of $F_{\mathrm{c}}, \zeta$, can be written in terms of the ratio of the normal force $F_{\mathrm{nc}}$ and the tangential force, $F_{\mathrm{tc}}$, by Eq. (9).

$\zeta=\frac{F_{\mathrm{nc}}}{F_{\mathrm{tc}}}$

By combining Eqs. (2) (5), (7) and (9), $F_{\mathrm{n}}$, can be written as shown in Eq. (10).

$F_{\mathrm{n}}=\zeta \varepsilon A_{\mathrm{c}}+\sigma A_{\mathrm{w}}$

And by combining Eqs. (3), (5), (7) and (8), the total tangential force, $F_{t}$, can be written as shown in Eq. (11).

$F_{\mathrm{t}}=\varepsilon A_{\mathrm{c}}+\mu \sigma A_{\mathrm{w}}$

Empirical evidence has supported this theoretical framework [8, 9], especially for sedimentary rocks where the cutting process can be described as plastic [3].

The same principles can also be applied to portable drilling resistance measurement systems. Stavropoulou and colleagues [9, 10] demonstrated that for the Drilling Force and Torque Measurement System, the drilling force is proportional to $d_{c}$ in the range of $0.03-0.55 \mathrm{~mm} / \mathrm{rev}$. A linear-proportional trend between drilling resistance and depth of cut, $\mathrm{d}_{\mathrm{c}}$, has also been confirmed for the DRMS torque measuring system [7] at the point that further research has expanded on the theories developed by Detournay and Defourny and adapted their equations to the DRMS torque system, using rectangular drill bits [5-7]. In such cases the total drilling resistance generated by a single cutter, $F_{n}$ (single cutter), can be calculated using Eq. (12) (modified from [7]) where $n$ is the number of cutters on the drill bit.

$F_{\mathrm{n}}($ singular cutter $)=\frac{\zeta \varepsilon d_{\mathrm{c}} w}{n}+\sigma w \lambda$

By integrating the total normal force of one cutter to take into account $\mathrm{n}$ cutters on the drill bit it is possible to calculate the weight-on-bit $W$, or drilling resistance [7] as described in Eq. (13).
$W=\zeta \varepsilon \frac{\mathrm{PR}}{\mathrm{RPM}} w+n \sigma w \lambda$

For the drill bits commonly used in conservation, the equation can be adapted further by dividing $W$ by the radius of the drill-bit, $r$ (equivalent to the length of a single cutter, $w$, in the case of drill bits with just two cutters) as described in Eq. (14).

$\frac{W}{r}=\zeta \varepsilon \frac{\mathrm{PR}}{\mathrm{RPM}}+n \sigma \lambda$

$\mathrm{W} / \mathrm{r}$ is a radius-independent drilling resistance. Pamplona and colleagues [1] describe a similar ratio as the 'diameter independent drilling resistance', when calculating the ratio between drilling resistance and the drill bit diameter. As the DRM system employed by Dagrain and colleagues also measured torque, it was possible to calculate $\zeta, \mu$ and $\varepsilon$ [8]. However, the majority of DRM machines currently available do not measure torque, and hence this approach is not always feasible. Nevertheless, it is possible to compare different materials or the effect of degradation or surface consolidation treatments by comparing the angular coefficient of the regression lines of the radius independent drilling resistance versus the ratio PR/ RPM assuming a constant $\zeta$ value. The ratio between the normal and tangential components of $F_{c}(\zeta)$ is a function of the back rake angle of the cutter (Fig. 1 shows generically the angle), $\theta$, and of the interfacial angle between cutter and the failed rock, $\psi$. For an ideal case where $\zeta$ is at a maximum value, it can be defined as shown in Eq. (15) [5-7, 11]

$\zeta_{\text {maximum }}=\tan (\theta+\psi)$

The interfacial friction angle between the cutter and failed rock, $\psi$, is not affected by the depth of cut or by the material type (in the range of materials tested in [11]). Assuming that $\psi$ varies insignificantly between the two materials and the same drill bit with a constant back rake angle is used, then the ratio of the normal and tangential components of $F_{c}, \zeta$, will not change from drilling one material to another. This would allow the change in intrinsic specific energy, $\varepsilon$, between two different holes to be determined by comparing the gradients of data plotted between $\mathrm{W} /$ $r$ versus PR/RPM.

As stated previously, the drilling resistance is often related to the uniaxial compressive strength. However, as there is no consistent relationship between these 


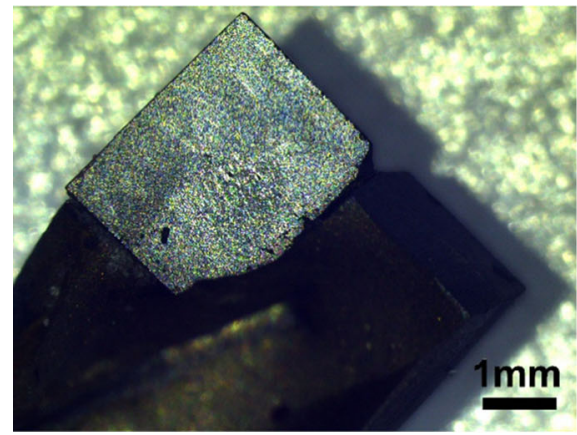

(a)

Fig. 2 Images of drill bit. a Optical image of drill bit chisel edge before drilling. b Optical image of drill bit after all experiments showing chipped region. c Scanning electron

two parameters, using drilling resistance to predict uniaxial compressive strength is problematic [1]. On the other hand, the intrinsic specific energy, $\varepsilon$, is theoretically and empirically considered a material's property [3-7] and therefore provides a more robust quantitative property to relate to the drilling resistance $[3,7]$.

\section{Experimental work}

\subsection{Materials and methods}

The effects of the penetration rate and rotational speed on drilling data was assessed using the cordless DRMS produced by SINT Technology s.r.l. (Italy). A new unused polycrystalline diamond coated, flat-tipped drill bit of $5 \mathrm{~mm}$ diameter with back rake angle of $0^{\circ}$, also supplied by SINT Technology s.r.l., was used for all investigations. The drill bit was formed of two diamond cutters attached to a tungsten-carbide bed and bonded to the steel drill rod using silver alloy. Optical and Scanning Electron Microscopy (SEM) revealed that before any testing the drill bit had a slight indent at its chisel edge and the tungsten-carbide beds were asymmetric (Fig. 2a). Nevertheless, in order to simulate conditions that engineers would likely encounter on-site, where it would not be practical to verify the drill bit with optical or electron microscopy, we chose to continue using the same drill bit.

Tests were carried out on two materials: a nonhomogenous, natural stone, and an artificial reference material. The natural stone was Bath stone which is a

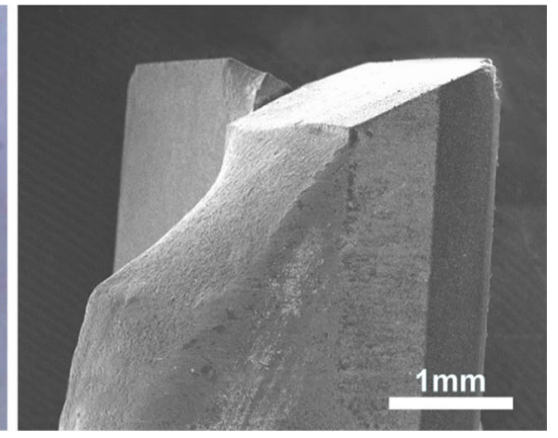

(c) (b)

microscopy image of drill bit after all experiments showing chipped edge. Cutting angle of $0^{\circ}$ is also visible

soft oolitic limestone widely used for construction in the south-west of England and of great importance within the conservation industry. The stone was provided as weathered ashlars by Wells Masonry Services Ltd. Blocks of stone were cut from 2 ashlars of appropriate size for clamping into the DRMS machine as shown in Fig. 3. In total 9 blocks of weathered stone, and 9 blocks of non-weathered stone surfaces were used for testing. Under weathering conditions, especially in areas where the atmosphere contains pollutants, Bath stone commonly forms a surface crust. This may consist of a dense layer of calcium carbonate and calcium sulphate and is identified as an initial spike in the drilling resistance corresponding to the surface region. For the purposes of this study data corresponding to the surface crust was not included in the data presented. This was achieved by, in most circumstances, removing data relating to the initial $0.8 \mathrm{~mm}$ of the drilled hole. In

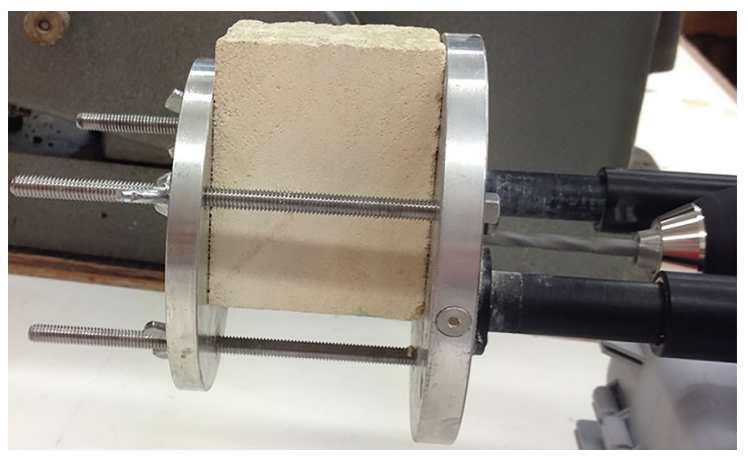

Fig. 3 Example of stone block secured using the DRMS plates and wing nuts 
some exceptional cases where the crust extended further down data up to $3 \mathrm{~mm}$ was removed.

The Artificial Reference Stone (ARS) used in these tests, was a ceramic material provided by SINT Technology srl, and was used for both drill bit wear correction and testing purposes. The material is considered a low-abrasive and homogenous material [12] with about three times the compressive strength of Bath stone. In fact, Bath stone has a compressive strength of $22.5 \mathrm{MPa}$ [13] whereas the ARS has a compressive strength of $61.3 \mathrm{MPa}$ [12].

All holes in the Bath stone were drilled up to a depth of $25 \mathrm{~mm}$ whereas holes in the ARS were limited to a depth of $10 \mathrm{~mm}$ by the thickness of the tile provided. All tests were performed at speeds of 100, 300, 600, and 900 revolutions per minute (RPM) and penetration rates of 5, 10, 20 and $30 \mathrm{~mm}$ per minute on Bath stone. On the ARS, tests were performed using the same combination of settings as used for the Bath stone but also including a higher penetration rate of $55 \mathrm{~mm}$ per minute.

The location of each hole drilled with a specific setting (i.e. a combination of rotational speed and penetration rate) was randomised to ensure that the effect of variations in properties of natural stones were minimised. A hole for wear correction was drilled in the ARS at $600 \mathrm{rpm}$ and $10 \mathrm{~mm} / \mathrm{min}$ after an average of 16 holes were drilled into the Bath stone.

Prior to any other processing, the data was corrected to account for drill bit wear. Average drilling resistance of ARS correction holes was used to assess a percentage increase in drilling resistance over time. It was necessary to make the assumption that wear would increase proportionally at other different penetration rates and rotational speed settings, and hence this could be effectively used for wear correction purposes. Since each hole in the Bath stone had the same drilled length (and significantly more holes were drilled in Bath stone compared to the ARS) the method used by Rodrigues and Costa for wear correction was adapted [14]. Instead of plotting the drilled length on the horizontal axis, the number of holes was used and plotted on the abscissae to find the rate of abrasion [14]. This simplification was realised using the average drilling resistance obtained for each correction hole in the ARS material which was plotted against the number of holes drilled during the drill bit history (see Fig. 4).

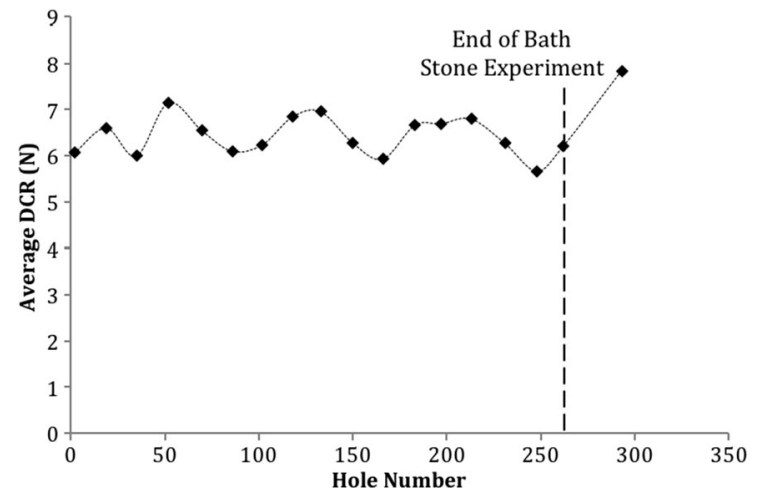

Fig. 4 Average drilling resistance versus hole number in artificial reference stone for wear-correction purposes

Data was averaged every $0.1 \mathrm{~mm}$ below the surface, producing a depth-specific average curve (DSA). In the case of non-weathered surfaces the first $0.2 \mathrm{~mm}$ were excluded from the depth-specific average curve, as this portion is known to produce data that isn't representative of the material properties of the stone. This effect is due to the cutting edges gradually becoming fully engaged in cutting, and is illustrated in the drilling resistance profile as an upsloping line. As previously mentioned, for weathered surfaces, on average, the first $0.8 \mathrm{~mm}$ were excluded from the calculation of the depth-specific average curve because of the crust with stronger mechanical properties that forms on the exposed stone surface due to weathering effects.

An average drilling resistance per unit radius (ADR_R) was also calculated by dividing Average Drilling Resistance (also known as ADR, calculated by averaging the depth-specific average curve at every $0.1 \mathrm{~mm}$ ) by the radius of the drill bit. The result of this procedure is illustrated in Fig. 5.

\subsection{Results}

\subsubsection{Drill bit and wear correction}

At the end of the study the drill bit displayed a chip near the chisel edge due to impact wear, as shown in Fig. 2b, c. The silver alloy used to bond the cutting surfaces to the main drill shaft showed signs of polishing, possibly due to the flow of cutting particles. No other significant alterations were observed on the main cutting edges. 


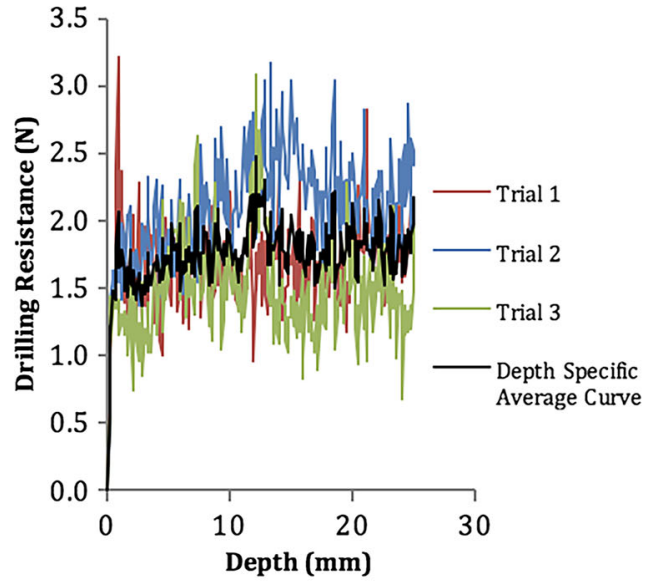

(a)

Fig. 5 Summary of drilling data processing: a drilling resistance against depth for the three trials performed on Bath stone at $10 \mathrm{~mm} / \mathrm{min}$ penetration rate and $600 \mathrm{RPM}$. The depth specific average resulting from averaging each of the three trials at each particular depth is displayed in black, and $\mathbf{b}$ drilling resistance

Data obtained from Bath stone did not require wearcorrection whereas correction was required when drilling the ARS. The rate of abrasion was determined from two subsequent wear correction holes, with 31 holes in between.

An increase of $2.5 \%$ in drilling resistance for correction (DRC) purposes in ARS was observed after drilling 292 holes in the Bath stone, as shown in Fig. 4. The average DRC was $6.49 \mathrm{~N}$, with a minimum of $5.67 \mathrm{~N}$ and a maximum of $7.15 \mathrm{~N}$. The DRC displayed a sinusoidal progression from the beginning to the end of the drilling in the Bath stone, as shown in Fig. 4. The reduced extent of the DRC increase suggests that Bath stone did not cause any significant wearing to the drill bit, and hence it was not necessary to correct the drilling data for Bath stone.

In comparison an increase of $26.2 \%$ was noted in the DRC over the 31 holes drilled in the ARS. Drilling data was therefore corrected using a rate of abrasion of $0.82 \%$ per hole drilled.

\subsubsection{Effects of penetration rate and rotation speed on drilling resistance}

The effect of penetration rate and rotational speed on the drilling resistance for both Bath stone and ARS is shown in Fig. 6. The graphs shows that higher penetration rates are associated with higher drilling

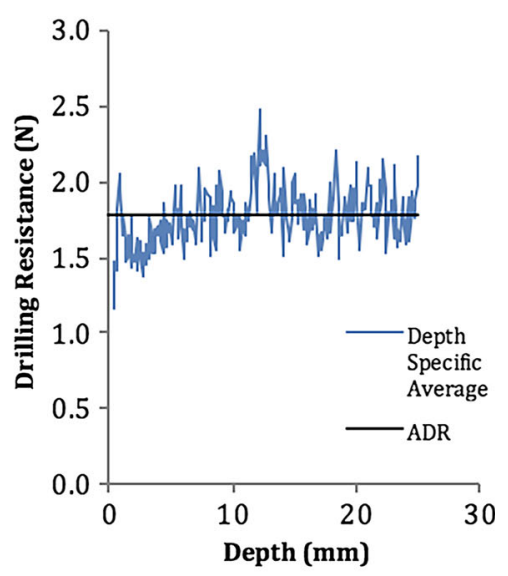

(b)

against depth for the depth specific average curve after the first $0.2 \mathrm{~mm}$ of depth was removed from the graph. Average drilling resistance of the depth specific average curve is illustrated in black

resistance values and, inversely, the higher rotation speed is associated with lower drilling resistance, where all other parameters remain constant. The highest drilling resistance was obtained at the setting combining the highest penetration rate and lowest rotation speed. As previously mentioned, the highest drilling resistance was obtained for the ARS.

Average Drilling Resistance per unit radius of the drill bit (ADR_R) for both Bath stone and ARS was plotted against the ratio PR/RPM as shown in Fig. 7. Results identify linear relationships between the ADR_R and the PR/RPM. Both the slope and y-intercept of the regression line for Bath stone are lower than the equivalent values for the ARS.

\subsubsection{Variability due to the combined effects of penetration rate and rotation speed}

Figure 8 shows the Coefficients of Variation (COV) for tests conducted at different penetration rates and rotation speeds. The variation in the ARS is smaller than in the Bath stone for all penetration rate and rotational speed settings. This is attributed to the natural variations present in the Bath stone (a natural material) and absent in the ARS (an artificial laboratory-made material). A flat pattern/relationship between $\mathrm{COV}$ and PR/RPM is discernible in both cases. 
Fig. 6 The variation of average drilling resistance with penetration rate and rotational speed on a Bath stone and $\mathbf{b}$ artificial reference stone

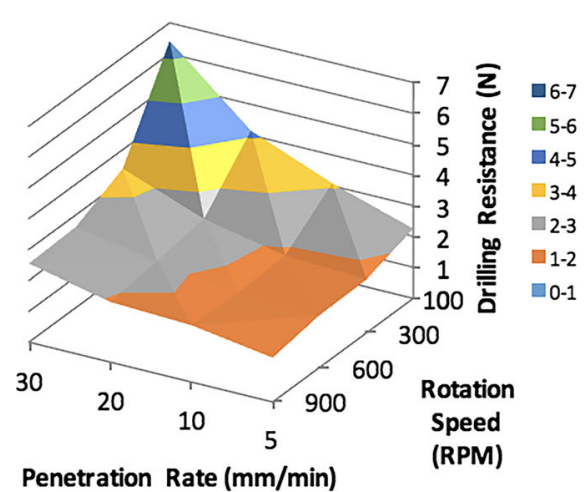

(a)

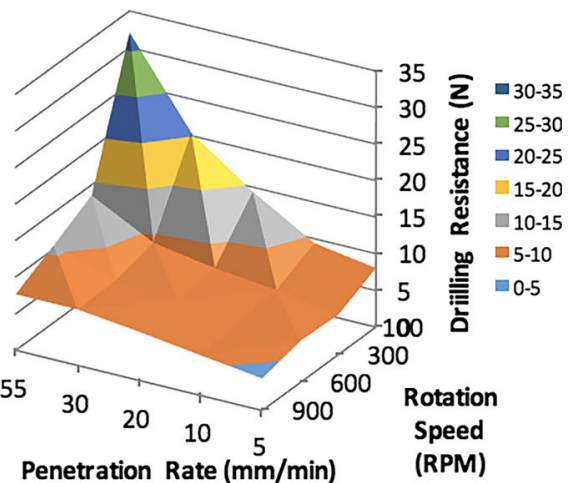

(b)

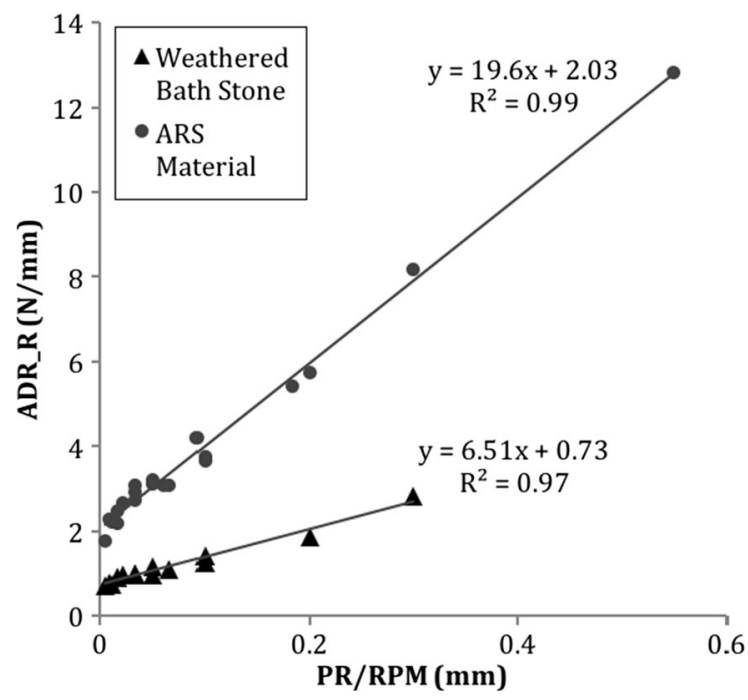

Fig. 7 Linear relationship between radius-independent average drilling resistance and different PR/RPM settings on Bath stone and artificial reference stone

\subsection{Discussion}

\subsubsection{Drill bit wear}

As it can be inferred by the sinusoidal shape of the ADR in Fig. 4, the drill bit was subject to a selfsharpening effect, similar to the effect previously reported for the use of diamond drill bits in oil rock drilling [8, 15]. This may be due to micro-level chipping producing a sharper edged diamond surface engaged in the cutting, increasing the drill bit's drilling efficiency to initial levels or similar [16]. This may account for the sinusoidal change of the drilling resistance in ARS during the tests on Bath stone. Since

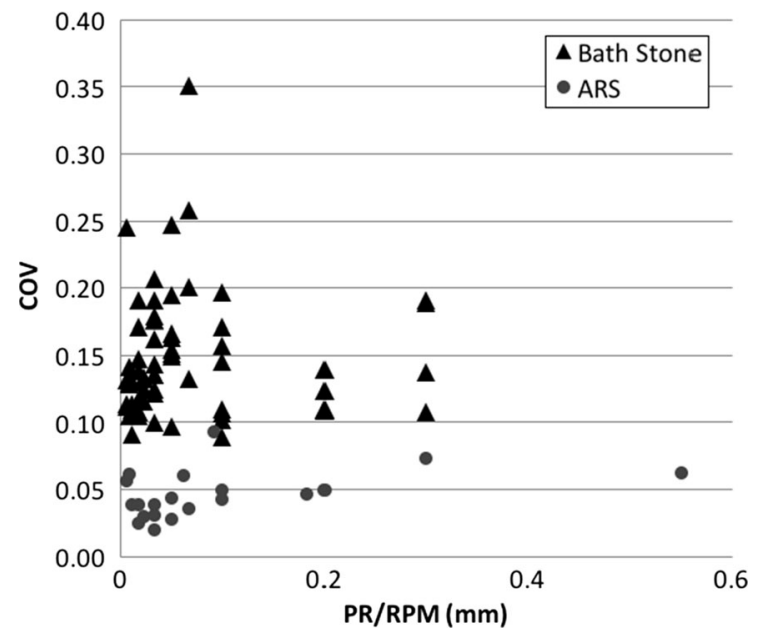

Fig. 8 Coefficient of variation at different PR/RPM settings on Bath stone and artificial reference stone

this effect is rarely observed with the DRMS and with other small diamond drill bits [14], it should be considered that changes in the drilling parameters may also play a role. SEM analysis of the drill bit showed effects of wear primarily around the chisel edge (Fig. 2b, c), where the small original indent transformed into a relatively large chipped area over the duration of the tests. This supports previous hypotheses suggesting that the main cause of increase in drilling resistance due to wear is the chisel edge effect [17]. It also confirms the presence of an initial crack which propagated while testing, resulting in the large chip observed.

No difference was detected (on average) between the first and last wear-correction drilling resistance holes during drilling in the Bath stone. This suggests that Bath stone does not abrade the drill bit 
significantly. The suggestion is supported by the absence of quartz (one of the most abrasive minerals in natural stones) in the Bath stone [14, 18].

Tests in the ARS caused the drill bit to wear, as demonstrated by the $26.2 \%$ increase in average DCR between the beginning and the end of the tests (Fig. 4). Even though this is often considered a non-abrasive material, its effect on the drill bit is quite evident. This may suggest that factors apart from the mineralogical composition of the material under investigation can also play a significant role in the wearing process.

It is noteworthy that in other studies excessive drill bit wear from ARS has not been reported [12, 14]. Figure 7 shows that high ratios of PR/RPM are associated with increased contact stresses on the tip of the drill bit. This suggests that one of the factors that may increase wear in the drill bit is the stress on the contact edges, which can be affected by the PR/RPM settings used. If this is the case, modifying PR/RPM settings may reduce wear even in abrasive materials.

For future experiments, it may be preferable to employ a suitable reference material which has a similar or lower wear rate on the drill compared to the stone or other substrate of interest. One way such a material could be identified is by comparing the relative values of drilling resistance in both materials at the same PR/RPM setting.

\subsubsection{Intrinsic specific energy and UCS}

The results obtained in this study confirm that penetration rate and drilling resistance are proportional when rotational speed is constant. However, it should be noted from both the Bath stone and the ARS, that the strength of the relationship decreases (as measured by the coefficient of variation, $R^{2}$ ) í speed $\geq 900 \mathrm{rpm}$. Such a decrease in $R^{2}$ can be noted when graphing ADR_R against PR at different RPM $(100,300,600$, and 900 in this study). This decrease in the strength of the relationship would be consistent with a change in failure mechanism from ductile to frictional attributed to high values of RPM. At such a point the drilling resistance no longer reflects the strength of the material and is a function of the frictional contact law. Such high values of RPM may also generate increased wear or polishing of the drill bit edge.

The very high $R^{2}$ values in Fig. 7, and the closeness of the points to the best fit line indicate the validity of the linear relationship between ADR_R and PR/RPM. The slope of the ARS graph is found to be higher than that of Bath stone. Since the angular coefficient of the regression line is proportional to the intrinsic specific energy of the material, this suggests that drilling the ARS (angular coefficient 19.6) requires more energy than cutting the same volume of material of the Bath stone (angular coefficient 6.51), and hence the ARS has a more strongly bonded microstructure. As mentioned earlier in the paper, the compressive strength of the ARS is about 2.7 times the compressive strength of the Bath stone (61.3 MPa for the ARS and 22.5 MPa for the Bath stone). This ratio is similar to the ratio of the intrinsic specific energy calculated for the two materials, equivalent to 3.01. The result confirms the relationship between ADR_R and PR/ RPM and illustrates how these values can be used to compare different material properties, independently from the drilling settings used.

These results also suggest that once the slope and $y$-intercept of the ADR-R and PR/RPM graph are determined for one drill bit type and material, average drilling resistance values obtained in the same material at different PR/RPM settings can be compared with each other. This would require the average drilling resistance measured at a certain $\mathrm{PR} / \mathrm{RPM}$ to be converted to another setting that it is desired to compare with using the regression line. This may allow engineers studying the same material to compare their results.

Figure 8 demonstrates that the variability in the data collected is a function of the homogeneity of the material drilled, and not a function of the drilling settings as exemplified by the ratio of PR/RPM. This is seen from the difference between COVs in the ARS and in the Bath stone, and from the fact that in both materials the COV values cluster around the same values, regardless of the settings used. It is also noteworthy that the variability appears to exist even in homogenous materials such as the ARS. This suggests that the DRMS system and/or the drill bit may play a role in the COV measured (not the DRMS settings). Overall, the tests show that changing penetration rate and rotation speed settings does not affect the variability of the drilling measurements and, hence, the PR/RPM settings can be tailored to the material drilled without affecting the accuracy or precision of the results. 


\section{Conclusions}

This study focused on the theoretical framework and experimental results supporting the relationship between UCS, drilling resistance and intrinsic specific energy, $\varepsilon$, of Bath stone and ARS. Results suggest that in DRM tests, the ratio of PR/RPM, along with the characteristics of the material under investigation, control the drilling resistance. Potential users of DRM systems should be aware that drilling hard stones requires relatively low PR/RPM ratios to minimise the drilling resistance (within the capacity of the system's load cell). Conversely, soft stones can be drilled with a higher PR/RPM ratio in order to increase the drilling resistance values to within the resolution of the DRMS and to minimise testing time. Higher PR/RPM settings for soft stones will produce higher drilling resistance values farther away from the machine's minimum threshold value for detection of force. This may also allow better data resolution and help limit possible errors in calibration (at higher drilling resistance values, such effects are minimised).

Penetration rate should be determined by considering the desired speed of the tests and the material hardness. Subsequently the desired PR/RPM ratio can be identified by adjusting rotational speed accordingly. An important conclusion from this study is that these values have been shown not to influence the variability of the drilling resistance results. Nevertheless, care should be taken to avoid measurements at high drilling resistances in order to reduce drill bit wear.

The results also demonstrated that:

1. No significant decrease in the sharpness of the diamond drill bit was observed following drilling over 250 holes in Bath stone at speeds varying from 100 to $900 \mathrm{rpm}$ and penetration rates from 5 to $30 \mathrm{~mm} / \mathrm{min}$. However, a sinusoidal fluctuation in average drilling resistance with holes drilled was noted (Fig. 4), which was hypothesised to correspond to a self-sharpening mechanism, which brings the sharpness of the drill bit closer to its initial level over time.

2. Penetration rate and drilling resistance were directly proportional to each other (at constant rotational speed) for both, Bath stone and ARS. Conversely, rotation speed and drilling resistance were inversely proportional (at constant penetration rate) for both, Bath stone and ARS. Drilling resistance was shown to be proportional to the ratio of PR/RPM for both ARS and Bath stone.

3. Varying the penetration rate between 5 and $55 \mathrm{~mm} / \mathrm{min}$ and the rotation speed between 100 and 900 RPM had no significant effect on the variability of the drilling resistance.

4. Variability in drilling resistance was accounted for by the non-homogeneity of the materials drilled.

Acknowledgements The authors would like to thank David Odgers, Odgers Conservation Ltd, and Alison Henry, Historic England for the helpful discussions. Thanks are also due to Wells Masonry Services Ltd for supplying samples of Bath stone. Special acknowledgement is given to Ursula Potter and Dr John Mitchell of the Microscopy and Analysis Suite (MAS), University of Bath, for assisting with electron microscopy. Data supporting this study are openly available from the University of Bath data archive at 10.15125/BATH-00443.

Open Access This article is distributed under the terms of the Creative Commons Attribution 4.0 International License (http:// creativecommons.org/licenses/by/4.0/), which permits unrestricted use, distribution, and reproduction in any medium, provided you give appropriate credit to the original author(s) and the source, provide a link to the Creative Commons license, and indicate if changes were made.

\section{References}

1. Pamplona M, Kocher M, Snethlage R, Aires Barros L (2007) Drilling resistance: overview and outlook. Z Ges Geowiss 158(3):665-676

2. Pesce GL, Morgan D, Odgers D, Henry A, Allen M, Ball RJ (2013) Consolidation of weathered limestone using nanolime. Proc ICE Constr Mater 166(4):213-228

3. Adachi J, Detournay E, Drescher A (1996) Determination of rock strength parameters from cutting tests. In: 2nd North American rock mechanics symposium, Montreal, American Rock Mechanics Association

4. Coudyzer C, Richard T (2005) Influence of the back and side rake angles in rock cutting. In: AADE 2005 national technical conference and exhibition, American Association of Drilling Engineers, Houston, TX

5. Dagrain F (2001) Influence of the cutter geometry in rock cutting: an experimental approach. University of Minnesota, Minneapolis

6. Dagrain F (2014) Scratching and micro-drilling tests. In: Building test expo. Stone Assistance, Brussells, Belgium

7. Dagrain F, Descamps T, Poot B (2010) Less-destructive testing of masonry materials: a comparison between 
scratching and drilling approaches. In: 8th international masonry conference, Dresden, Germany

8. Detournay E, Defourny P (1992) Phenomenological model for the drilling action of drag bits. J Rock Mech Min Sci Geomech Abstr 29(4):242

9. Stavropoulou M (2006) Modeling of small-diameter rotary drilling tests on marbles. Int $J$ Rock Mech Min Sci 43(7):1034-1051

10. Stavropoulou M, Giannakopoulos K, Exadaktylos G (2004) Experimental and numerical study of mechnical cutting of dionysus marble. In: 7 th national congress on mechanics, Chania

11. Mitaim S, Dagrain F, Richard T, Detournay E, Drescher A (2004) A novel apparatus to determine the rock strength parameters. In: Proceedings of the 9th national convention on civil engineering, Petchburi, Thailand

12. Valentini E, Benincasa A, Rescic S (2008) DRMS cordless repeatability and uncertainty evaluation of test results. SINT Technology, Calenzano
13. Bath Limestone (2016) External Works Index (Online)]. https://www.externalworksindex.co.uk/entry/35705/ Realstone/Bath-limestone/. Accessed 05 Jan 2016

14. Rodrigues DJ, Costa D (2004) A new method for data correction in drill resistance tests for the effect of drill bit wear. Int J Restor 10(3):1-18

15. Radtke B, Smith M, Riedel R, Daniels D, Gwilliam (1999) New high strength and faster drilling TSP diamond cutters. In: 1999 Oil and gas conference-technology options for producers' survival

16. Azar J, Samuel G (2007) Drilling Engineering. PennWell Corp, Tulsa, Oklahoma, USA

17. Mimoso J, Costa D (2005) A new DRMS technique for the laboratory. In: 8th International conference on "non destructive investigations and micronalysis for the diagnostics and conservation of the cultural and environmental heritage"

18. Costa D, Magalhaes A, Veiga R (2011) Characterization of mortars using DRMS: tests on field panels samples. In: 2nd conference on historic mortars-HMC 2010 and RILEM TC 203-RHM final workshop, RILEM Publications SARL 